\title{
Maksiller Anterior Dişler Arasında Görülen Diastemaların Direkt Kompozit Rezinle Restorasyonu; İki Olgu Sunumu
}

\author{
Elif KARAPIÇAK 國 ${ }^{1}$, Kıvanç DÜLGER 國 ${ }^{1}$
}

\begin{abstract}
Öz
Genellikle estetik problemlere sebep olan orta hat diastemalarına sıklıkla rastlanılmaktadır. Pek çok tedavi seçeneği bulunsa da direkt kompozit rezinlerle restorasyonu sıklıkla tercih edilmektedir. Diastema kapatılmasında direkt kompozit rezinler noninvaziv bir yöntemdir. Kısa sürede tamamlanan restorasyonların diğer estetik tedavi seçeneklerine göre pahalı olmaması ve tatmin edici estetik sonuçlar vermesi bu tedavi seçeneğinin sıklıkla tercih edilmesine yol açmaktadır. $\mathrm{Bu}$ olgu raporunda orta hat diasteması bulunan iki vakanın kompozit rezinlerle direkt restorasyonu tamamlanmıştır. Tedavi bitiminde elde edilen memnun edici sonuçlara ilave olarak yapılan 18 aylık kontrollerde herhangi bir probleme rastlanılmamıştır. Orta hat diastemalarının dental kompozit rezinlerle direkt olarak kapatılmasında uzun süreli memnun edici sonuçlar elde edilmektedir.
\end{abstract}

Anahtar Kelimeler: Kompozit dental rezin; dental estetik; diyastem.

\section{Closure of Midline Diastema with Direct Composite Restorations; Two Case Reports}

\begin{abstract}
Midline diastemas which lead to esthetical problems generally are encountered frequently. Although they have a lot of treatment options, the closure of midline diastemas by direct dental composites is prefered. The closure of midline diastemas with direct dental composites is a noninvasive treatment option. They may be completed in a short time; they are cheaper than other treatment options and they give satisfactory results. All of these results make this treatment to be preferable. In this case report two midline diastemas are closed by direct composite build-ups. In addition to immediate satisfactory results, during the 18 months of follow-ups no problems were encountered. The closure of midline diastemas by direct composites is preferred because of their long-term satisfactory results.
\end{abstract}

Keywords: Composite dental resin; dental esthetics; diastema.

\section{GíRiş}

Üst çenedeki kesici dişler arasındaki 0,5 mm'den fazla olan interdental boşluk orta hat diasteması olarak tanımlanır (1). Üst çene mesial diastemalı bir hasta için tedavi planı belirlenmeden önce, diş hekiminin diastema etiyolojisini net olarak anlaması gerekir. Diş sayısındaki eksiklik, fazlalık, dişlerin boyutundaki anomaliler, genişlemiş bir labiyal frenulum varlığı, parafonksiyonel alışkanlıklar (dil itme veya parmak ısırma gibi) veya ilerlemiş periodontitis varlığı bu sebepler arasında olabilir (1). Orta hat diastemaları, estetik bir problem oluşturmanın yanında maloklüzyona da sebep olmaktadır. Bu nedenle, bu boşlukların estetik olarak kapatılması diş hekimliğinde yaygındır (2).

Diastemaların kapatılmasında multidisipliner tedaviler uygulanabilir (3). Sıklıkla ortodontik tedaviler endikedir fakat diş oranlarındaki farklılıklardan dolayı tedavi bittikten sonra bile diastemalar kalabilir. Genellikle, ortodontik tedavilerin maliyeti fazladır ve zaman alıcıdır. Hastalar ise, ileri yaşlarda braket takmayı kabul etmeyebilirler (4). Bu bireylerde bulunan diastemaların kapatılması için seramik vener ve kompozit rezin sistemleri tatmin edici şekilde kullanılmaktadır (5).

Üst çenenin alt çeneye göre daha yüksek bir orta hat diastema prevalansına sahip olduğu bildirilmiştir (6). Orta hat diastemasına sahip hastalar estetik kaybın yanı sıra konuşma bozuklukları, dudak ısırma ve olumsuz psikolojik etkilerden de şikayet edebilirler (7).

1 Karadeniz Teknik Üniversitesi Restoratif Diş Tedavisi Trabzon,Türkiye 
Çok sayıda tedavi seçeneği göz önüne alındığında, diastemaların nasıl tedavi edileceği etiyolojik, ekonomik, zaman kullanılabilirliği ve hastaların istekleri gibi pekçok faktöre bağlıdır (8). Seramik restorasyonlar oldukça estetik materyaller olmalarına rağmen, tedavileri çok seanslıdır ve maliyetleri oldukça yüksektir (9). Kompozit rezinlerin maliyetinin düşük olması ve tek seansta uygulanabilmesi hastaların bu tedavileri seçmesindeki başlıca nedenler arasındadır. $\mathrm{Bu}$ olgu raporu, direkt kompozit rezin uygulaması yapılmış orta hat diastemalı 2 adet vakanın 18 aylık takibini içermektedir.

\section{OLGU SUNUMU \\ OLGU 1:}

18 yaşında kadın hasta, ön bölgedeki estetik şikayeti nedeniyle kliniğimize başvurdu. Yapılan detaylı anamnezde hastanın herhangi bir hastalığının olmadığı belirlendi. Oral muayene sonucu hastanın maksiller ön bölgede orta hat diastemasının olduğu gözlemlendi (Resim 1).

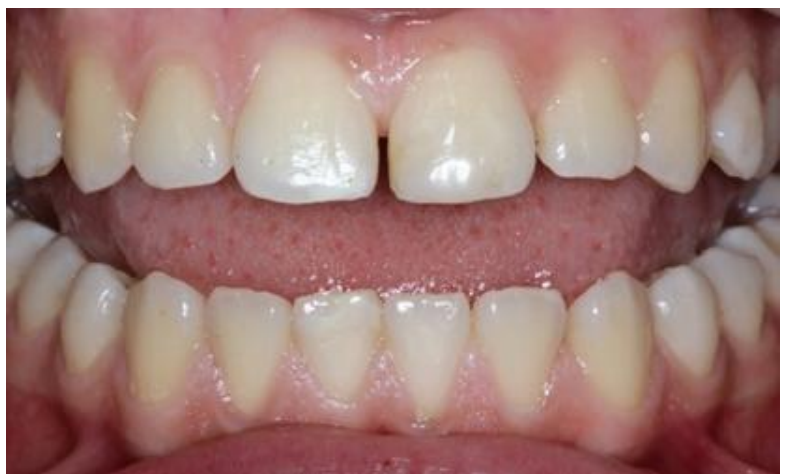

Resim 1: Hastanın kliniğe başvurduğundaki ilk hali

Dişlerin klinik ve radyografik muayenesi sonucu herhangi bir diş çürügüüne ve periodontal soruna rastlanmadi. Hastaya çeşitli tedavi alternatifleri sunuldu ve hasta daha konservatif bir yaklaşım olan kompozit rezin ile diastemaların direkt restorasyonunu tercih etti. Tedavi için onam alındı. Renk seçiminde Vita klasik renk skalası kullanıldı ve dişlerin renk tonunun A2 olduğu belirlendi. Renk tonunun dişe en yakın şekilde olabilmesi için mine ve dentin için ayrı opaklıkta renkler seçildi. Yan dişlere şeffaf bant takılarak maksiller orta keserler izole edildi ve dişlerde hiçbir preperasyon yapılmadan \%37'lik fosforik asit (Etching Jel, President Dental, Almanya) ile 20 sn pürüzlendirildi. Asit 20 sn boyunca suyla yıkandı ve dişler hafif hava ile kurutuldu. Tek şişe (Single Bond Universal Adhesive, 3M ESPE, Amerika) bond kullanma talimatına uygun şekilde kullanılarak 20 sn uygulandi. 5 sn kurutuldu ve 10 sn boyunca LED cihazı (Elipar S10, 3M ESPE, Amerika) ile polimerize edildi. Dental kompozit (Estelite Sigma Quick, Tokuyama Dental, Japonya) uygulanarak polimerize edildi ve restorasyon tamamland1. Cila diskleri (Sof-lex, 3M ESPE, Amerika) kalın grenliden ince grenliye doğru sirasıyla kullanılarak restorasyon bitirildi (Resim 2).

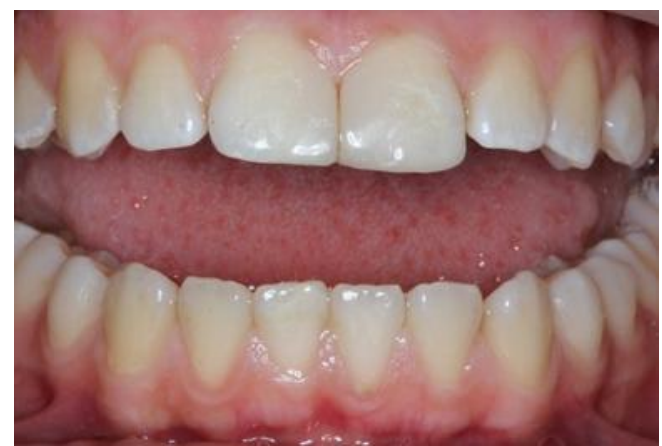

Resim 2: Hastanın tedavisi tamamlandığında ağız içi görüntüsü

Hasta oral hijyen açısından motive edildi ve kontroller için bilgi verildi. 18 ay sonunda hastanın yapılan kontrollerinde herhangi bir probleme rastlanmadı (Resim 3).

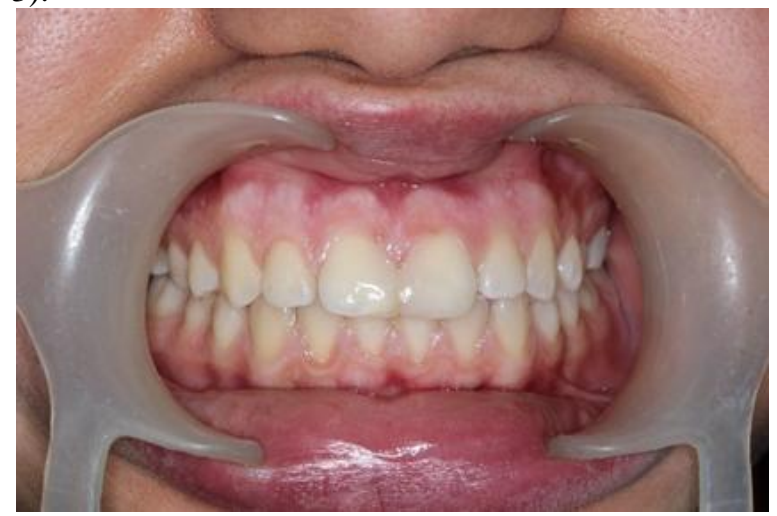

Resim 3: Hastanın tedaviden 18 ay sonraki ağız içi görüntüsü

\section{OLGU 2:}

19 yaşında kadın hasta ön bölge estetik şikayeti nedeniyle kliniğimize başvurdu. Yapılan detaylı anamnezde hastanın herhangi bir hastalığının olmadığı belirlendi. Oral muayene sonucu hastanın ortodontik tedavisinin henüz bitirildiği buna rağmen üst çene ön bölgede orta hat diastemasının ortodontik olarak kapatılamadığı belirlendi (Resim 4).

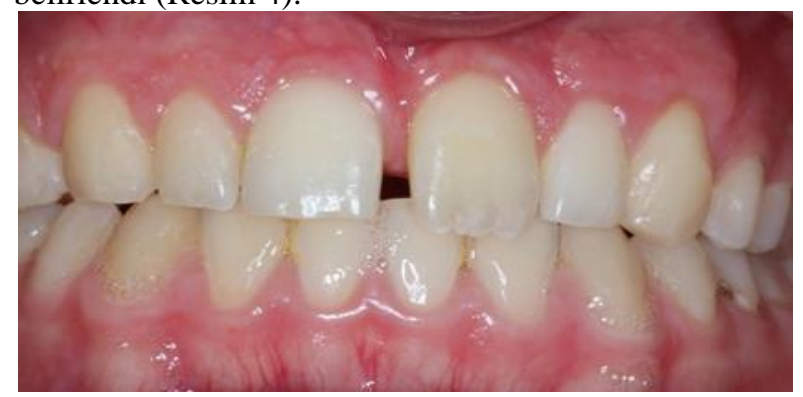

Resim 4: Hastanın kliniğe başvurduğundaki ilk hali

Tedavi için onam alındı. Dişlerin klinik ve radyografik muayenesi sonucu herhangi bir diş çürüğüne rastlanmamasına rağmen periodontal sorun bulunmaktaydı. Periodontal tedavinin ardından iyileşme sağlanınca restoratif tedavi aşamasına geçildi. Ortodontik tedavi yardımıyla sürdürülmüş olan maksiller sol orta keser diş ile sürmüş durumda ve bir süredir kullanımda olan maksiller sağ orta keser diş arasında minimal olarak şekil ve boyut farkına rastlandı. Hastaya çeşitli tedavi alternatifleri sunuldu. Hasta, daha konservatif bir 
yaklaşım olan kompozit rezin ile diastemanın direkt olarak restorasyonunu tercih etti. Renk seçiminde Vita klasik renk skalası kullanıldı ve renk tonu A2 olarak belirlendi. Renk tonunun dişe en yakın şekilde olabilmesi için mine ve dentin için ayrı opaklıkta renkler seçildi. Yan dişlere şeffaf bant takılarak ve hiçbir preperasyon yapılmadan dişler \%37'lik fosforik asit (Etching Jel, President Dental, Almanya) ile 20 sn pürüzlendirildi. Asit 20 sn boyunca suyla uzaklaştırıldı ve dişler hafif hava ile kurutuldu. Adesiv olarak tek şişe (Single Bond Universal Adhesive, 3M ESPE, Amerika) bond kullanma talimatına uygun şekilde kullanılarak 20 sn boyunca LED cihazı (Elipar S10, 3M ESPE, Amerika) ile polimerize edildi. Dental kompozit (Estelite Sigma Quick Composite, Tokuyama Dental, Japonya) uygulanıp polimerize edildi. Cila diskleri (Sof-lex, 3M ESPE, Amerika) kalın grenliden ince grenliye doğru sırasıyla kullanılarak restorasyon bitirildi (Resim 5). 18 ay sonunda yapilan kontrollerde herhangi bir probleme rastlanmadı (Resim $6)$.

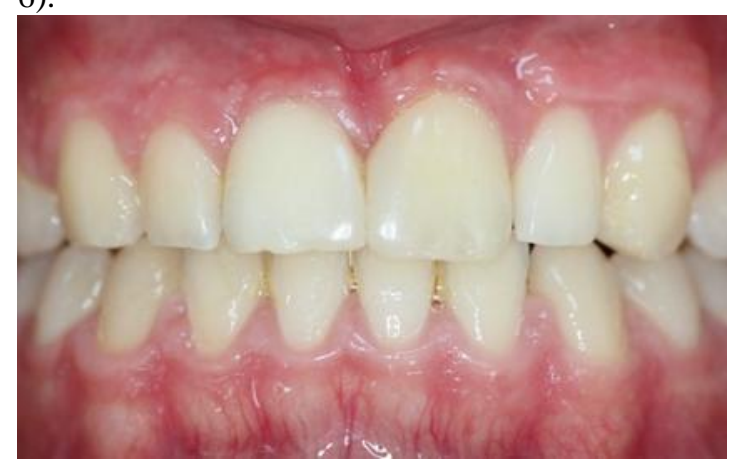

Resim 5: Hastanın tedavisi tamamlandığında ağız içi görüntüsü

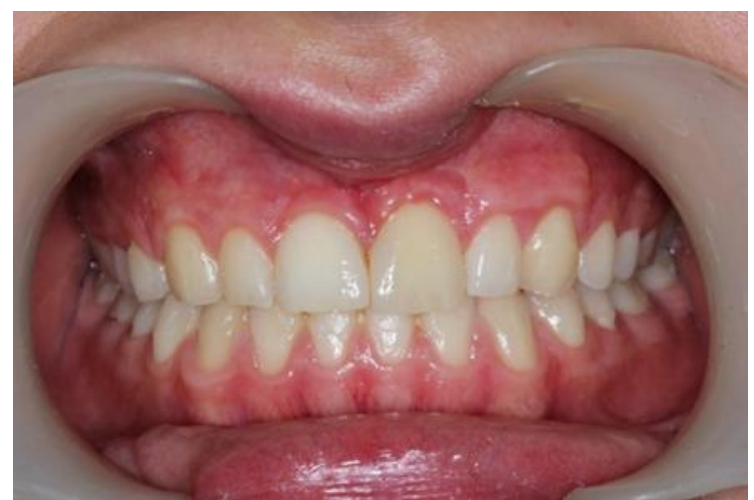

Resim 6: Hastanın tedaviden 18 ay sonraki ağız içi görüntüsü

\section{TARTIŞMA}

Direkt kompozit restorasyonlar, dişe destek sağlama ve koruma, yerleştirme ve uyumlandırma kolaylığı, oral hijyen prosedürlerinin kolaylıkla yapılması ve geri dönüşümü olan bir tedavi olması avantajlarına sahiptir (10). Restore edilecek diş yapısının doğrudan kompozit restorasyonu, tam seramik kuronlara göre birçok avantaja sahiptir (10). Dental seramik kuronlar; yüksek kırılma direnci ve renk stabilitesinin iyi olması gibi avantajlara sahiptir (11). Dental kompozit rezinler ise dental seramiklerden daha ucuz, kısa sürede tamamlanabilir, noninvaziv bir seçenektir ve antagonist dişi seramik materyallere göre daha az aşındırma gibi avantajlara sahiptir (12). Bu vakalarda da dental kompozit restorasyonların direkt olarak uygulanması bu sebeplerden dolayı tercih edilmiştir. Yapılan restorasyonların kırık, renkleşme gibi durumlarda onarılabilir olması da tercih sebepleri arasındadır (13).

Üst çenede dişler arasındaki diastemaların tedavisi kompozit rezin olabileceği gibi ortodontik tedavi de seçenekler arasındadır. İkinci vakamızda olduğu gibi bazı durumlarda ortodontik tedavilerden sonra da dişler arasında diastemalar kalabilmektedir. $\mathrm{Bu}$ diastemalar estetik ve konuşma problemlerine yol açabilmektedir (14). Hastamız ortodontik tedavi sonrasında estetik şikayetiyle başvurmuştur. Ortodontik tedavi sonrasında diastemaların kompozit restorasyonlarla tedavisi de tercih edilen bir seçenektir. Orta hat diastemalarının direkt restorasyonları sirasında silikon anahtar uygulanarak palatal rehberlik sağlanması yaygındır (15). Fakat bu vakalarda restorasyon süresini kısalttığı için herhangi bir rehberlik kullanılmamıştır. Restorasyonlar şeffaf bantların yardımıyla restore edilerek tamamlanmıştır. Kısa sürede tamamlanması gereken bu tarz vakalarda uzun süreli tatmin edici sonuçlar alınabilmektedir. Ayrıca ön bölge restorasyonlarında kullanılan dental kompozitler estetik özellik göstermelidir ve manipülasyonları kolay olmalıdır (13). Bu amaçla kullandığımız dental kompozit, nanofil özelliktedir ve sonucu tatmin edicidir.

Yapılan bir çalışmada nanokompozitlerle restore edilen diastemaların, 4 yil sonunda renk uyumu, kenar renkleşmesi, anatomik form, yüzey özellikleri ve adaptasyon açısından başarı oranı \%90'dır (15). Başka bir çalışmada ise direkt kompozitlerle restore edilen diastemaların beş yıllık başarısı \%84,6 olarak belirlenmiştir (16). 18 ay sonunda yaptığımız kontrollerde dişlerdeki görünüm estetiktir. Herhangi bir kırık, renkleşme, sekonder diş çürüğü veya marjinal sızıntı belirlenmemiştir. Kullanılan iyi bir teknik ve materyal, deneyimli bir diş hekimi ve hastanın da tedaviye karşı olumlu tutumuyla başarılı restorasyonlar elde edilmektedir.

Çıkar çatışması: Herhangi bir çıkar çatışması veya finansal destek yoktur.

Yazar katkıları: Fikir/Kavram:K.D.; Tasarım:K.D.; Veri toplama ve/veya işleme: E.K.; Analiz ve/veya yorum: K.D.; Literatür Taraması: E.K.; Makale Yazımı: E.K.; Eleştirel İnceleme: K.D.

Araştırma ve yayın etiği beyanı: Olgulardan bilgilendirilmiş onam alınmış olup çalışma araştırma ve yayın etiğine uyularak yazılmıştır.

\section{KAYNAKLAR}

1. Chu $\mathrm{CH}$, Zhang CF, Jin LJ. Treating a maxillary midline diastema in adult patients: a general dentist's perspective. J Am Dent Assoc. 2011; 142(11): 125864.

2. Kabbach W, Sampaio CS, Hirata R. Diastema closures: a novel technique to ensure dental proportion. J Esthet Restor Dent. 2018; 30(4): 275-80.

3. Romero MF, Babb CS, Brenes C, Haddock FJ. A multidisciplinary approach to the management of a 
maxillary midline diastema: a clinical report. J Prosthet Dent. 2017; 119(4): 502-5.

4. Saratti CM, Krejci I, Rocca GT. Multiple diastema closure in periodontally compromised teeth: how to achieve an enamel-like emergence profile. J Prosthet Dent. 2016; 116(5): 642-6.

5. Korkut B, Yanikoglu F, Tagtekin D. Direct midline diastema closure with composite layering technique: a one-year follow-up. Case Rep Dent. 2016; 2016(1): 1-5.

6. Kaimenyi JT. Occurrence of midline diastema and frenum attachments amongst school children in Nairobi, Kenya. Indian J Dent Res. 1998; 9(2): 67-71.

7. Kerosuo H, Hausen H, Laine T, Shaw WC. The influence of incisal malocclusion on the social attractiveness of young adults in Finland. Eur J Orthod. 1995; 17(6): 505-12.

8. Barros de Campos PR, Maia RR, Rodrigues de Menezes L, Barbosa IF, Carneiro da Cunha A, Da Silveira Pereira GD. Rubber dam isolation--key to success in diastema closure technique with direct composite resin. Int J Esthet Dent. 2015; 10(4): 56474.

9. Calamia V, Pantzis A. Simple case treatment planning: diastema closure. Dent Clin North Am. 2015; 59(3): 655-64.

10. Milosevic A. Clinical guidance and an evidencebased approach for restoration of worn dentition by direct composite resin. Br Dent J. 2018; 224(5): 30110.

11. Gresnigt MM, Kalk W, Özcan M. Randomized clinical trial of indirect resin composite and ceramic veneers: up to 3-year follow-up. J Adhes Dent. 2013; 15(2): 181-90.

12. Krämer N, Kunzelmann KH, Taschner M, Mehl A, Garcia-Godoy F, Frankenberger R. Antagonist enamel wears more than ceramic inlays. J Dent Res. 2006; 85(12): 1097-100.

13. Goyal A, Nikhil V, Singh R. Diastema closure in anterior teeth using a posterior matrix. Case Reports in Dentistry. 2016; 2016(2): 1-6.

14. Kamble A, Shah P, Velani PR, Jadhav G. Laserassisted multidisciplinary approach for closure and prevention of relapse of midline diastema. Indian $\mathbf{J}$ Dent Res. 2017; 28(4): 461-4.

15. Demirci M, Tuncer S, Öztaş E, Tekçe N, Uysal Ö. A 4-year clinical evaluation of direct composite buildups for space closure after orthodontic treatment. Clin Oral Investig. 2015; 19(9): 2187-99.

16. Frese C, Schiller P, Joerg H, Wolff D. Recontouring teeth and closing diastemas with direct composite buildups: a 5-year follow-up. J Dent. 2013; 41(11): 979-85. 